\title{
Phosphorus Limitation on Primary Production in Archean Ecosystems
}

\author{
$\mathrm{J} \mathrm{HAO}^{1,2}, \mathrm{AH} \mathrm{KNOLL}^{3}, \mathrm{~F} \mathrm{HUANG}^{4}, \mathrm{~J} \mathrm{SCHIEBER}^{5}, \mathrm{RM}^{2}$ \\ HAZEN $^{6}$, I DANIEL ${ }^{1}$
}

${ }^{1}$ Université Lyon 1, Ens de Lyon, Villeurbanne, France

${ }^{2}$ Rutgers University, New Brunswick NJ, USA

${ }^{3}$ Harvard University, Cambridge MA, USA

${ }^{4}$ Rensselaer Polytechnic Institute, Troy NY, USA

${ }^{5}$ Indiana University, Bloomington, IN, USA

${ }^{6}$ Carnegie Institution for Science, Washington DC, USA

Several lines of evidence point to low rates of net primary production (NPP) in Archean oceans. However, whether Archean NPP was limited by electron donors or nutrients, particularly phosphorus (P), and how these factors might have changed over a billion years of recorded Archean history, remains contentious. One major challenge is to understand quantitatively the biogeochemical cycling of $\mathrm{P}$ on the early Earth

Here, we estimated the weathering flux of $\mathrm{P}$ to the oceans as a function of temporally increasing continental emergence and elevation through Archean time. In addition, we conduct thermodynamic and kinetic simulations to understand key processes of $\mathrm{P}$ cycling within the Archean ocean, including seafloor weathering, recycling of organic $\mathrm{P}$, the solubility and precipitation of secondary phosphate minerals, and the burial diagenesis of $P$ precipitates.

Optimistic assumptions about the recycling efficiency of $\mathrm{P}$ on the Archean Earth lead us to estimate that by the end of the eon the total flux of $\mathrm{P}$ (continental weathering + recycling) could have supported NPP at levels up to $7 \%$ of the modern. The total flux of $\mathrm{P}$ would have been much lower on the early and middle Archean Earth, whereas fluxes of electron donors could have been higher, suggesting very low productivity and P-limitation of marine ecosystems during much of the eon. Comparing our estimates of NPP as limited by P supply with the estimate by Ward et al. (2019), in which NPP was limited by electron donors and metabolic efficiency, there could have been a transition between P-limited productivity in the early to middle Archean to electron donorlimitation closer to the eon's end (assuming no oxygenic photosynthesis). Once oxygenic photosynthesis reached ecological significance, probably near the end of the Archean, our estimated flux of $\mathrm{P}$ would allow rapid oxidation of atmosphere. 